\title{
NARRATIVAS DE EXPERIÊNCIAS EDUCACIONAIS DE UM GRUPO DE MIGRANTES
}

\author{
NARRATIVES OF EDUCATIONAL EXPERIENCES OF A GROUP OF MIGRANTS
}

Filomena Maria Arruda Monteiro'

Carlos Alberto Caetano ${ }^{2}$

\begin{abstract}
Resumo: Este artigo é recorte de uma pesquisa 3 maior, tendo como temática central a diversidade. Tratamos aqui de algumas experiências de educação escolar vivenciada por um grupo de migrantes, focando as problemáticas postas na constituição dos atendimentos pelas políticas públicas. Para a realização do estudo adotamos a pesquisa narrativa, trazendo fragmentos de relatos narrativos de estudantes migrantes haitianos que frequentavam três escolas estaduais em Cuiabá-MT. Os significados evidenciados nos relatos indicam necessidades de institucionalização de projetos e de reorientações curriculares voltadas aos interesses dos coletivos de indivíduos que se encontram em condições de desigualdade e exclusão social Concluimos este estudo sugerindo o desafio de mergulharmos em histórias e narrativas que nos ajudem a interferir de maneira positiva nestes percalços que os povos migrantes vêm enfrentando.
\end{abstract}

Palavras chaves: Narrativas. Experiências educacionais. Migrantes.

Abstract: This article is a cut of a larger research, having as central theme the diversity. We deal here with some experiences of school education experienced by a group of migrants, focusing on the problems posed in the constitution of the attendance of by public policies. For the study we adopted narrative research, bringing fragments of narrative accounts of Haitian migrant students who attended three state schools in Cuiabá-MT. The meanings evidenced in the reports indicate needs of institutionalization of projects and curricular reorientation directed to the interests of the collectives of individuals who find themselves in conditions of inequality and social exclusion. We concluded this study by suggesting desafio to dive into stories and narratives that help us to interfere in a positive way in these setbacks that the migrant peoples have been facing.

Keywords: Narratives. Educational experiences. Migrants.

Resumen: Este artículo es parte de una investigación más amplia, con la diversidad como tema central. Se trata aquí de algunas experiencias de educación escolar vividas por un grupo de migrantes, centrándonos en los problemas planteados en la constitución de la asistencia por parte de las políticas públicas. Para llevar a cabo el estudio, adoptamos una investigación narrativa, trayendo fragmentos de informes narrativos de estudiantes migrantes haitianos que asistieron a tres escuelas públicas en Cuiabá-MT. Los significados evidenciados en los informes señalan la necesidad de institucionalización de proyectos y reorientaciones curriculares dirigidas a los intereses de colectivos de individuos que se encuentran en condiciones de desigualdad y exclusión social. Concluimos este estudio sugiriendo el desafío de sumergirnos en historias y narrativas que nos ayuden a de manera positiva en estos obstáculos que enfrentan los pueblos migrantes.

Palabras clave: Narrativas. Experiencias educativas. Migrantes.

\footnotetext{
${ }^{1}$ Doutora em Educação pela Universidade Federal de São Carlos e professora Associada da Universidade Federal de Mato Grosso. E-mail: filarruda@hotmail.com. Orcid: https://orcid.org/0000-0002-2991-7416.

2 Doutor em Educação pela Universidade Federal de Mato Grosso e professor de sociologia e filosofia na Rede Pública Estadual de Educação do Estado de Mato Grosso. E-mail: caeettao@gmail.com. Orcid: http://orcid.org/0000-0003-2376-2297.

3 Projeto de pesquisa intitulado "Políticas educacionais da diversidade: narrativas de experiências de docentesativistas por uma pedagogia do multiculturalismo" aprovado pelo Comitê de ética.
} 


\section{INTRODUÇÃO}

As discussões abordadas neste texto são recortes de uma pesquisa maior, tendo como temática central a diversidade. Tal temática tem se apresentado como um campo complexo e multifacetado, que implica disputa de concepções teórico-metodológica, assim como posicionamento político, envolvendo dimensões econômicas, sociais e históricas de diversos grupos sociais. Dentre esses grupos sociais com suas singularidades, potencialidades e vulnerabilidade, queremos destacar o fenômeno da migração no Brasil, em que atualmente vivem migrantes oriundos de diversos países da África, América do Sul, Caribe, dentre outros, revelando um aumento considerável nos fluxos entre os anos de 2010 a 2015.

Assim, o Brasil passa a ter um marco-jurídico, em relação à migração com a Lei 13.445/2017, "que institui a Lei de Migração", no seu Art. $1^{\circ}$ das disposições gerais diz: "Esta Lei dispõe sobre os direitos e os deveres do migrante e do visitante, regula a sua entrada e estada no País e estabelece princípios e diretrizes para as políticas públicas para o emigrante.". Podemos mencionar ainda os vários dispositivos legais ratificados pelo Brasil sobre o migrante e refugiados como; Convenção da ONU sobre a Eliminação de todas as Formas de Discriminação Racial (1966), ratificada pelo Brasil em 27 de março 1968.

O mais importante da lei 13.445/2017, é que traz um marco político-educacional:

Art. $4^{\circ}$ Ao migrante é garantida no território nacional, em condição de igualdade com os nacionais, a inviolabilidade do direito à vida, à liberdade, à igualdade, à segurança e à propriedade, bem como são assegurados", parágrafo X - "direito à educação pública, vedada a discriminação em razão da nacionalidade e da condição migratória (BRASIL, 2017).

Diante deste contexto é importante ressaltar o papel imprescindível dos movimentos sociais, para garantia destes dispositivos principalmente o Movimento Negro em Cuiabá-MT, que abraçou a luta para garantir educação para os migrantes estrangeiros, desde suas entradas no Estado sobretudo os haitianos que aqui estavam em grande número em função do enfrentamento do terremoto em 2010, e pelas motivações relacionais deixadas pela atuação da Missão das Nações Unidas para a Estabilização no Haiti - MINUSTAH.

Ainda no mesmo contexto jurídico-político as leis federais 10.639/2003 e 10.645/2008 criam um marco legal que nos permitiu instaurar os processos de incorporação das identidades a partir das culturas de origens, isto acontece em função dos possíveis alcances que ficam postos nos contextos das pretensões e tensões causadas pelos dispositivos legais, a lei 10.639/2003" que altera a Lei No 9.394, de 20 de dezembro 1996, estabelece as diretrizes e bases da educação nacional, para incluir no currículo oficial da Rede de Ensino a obrigatoriedade da temática "História e Cultura Afro-Brasileira". Além disso, como podemos analisar no texto de políticas públicas educacionais para as relações étnico-raciais e quilombolas, esta lei abre para valorização das culturas diáspora africana no Brasil.

Quanto à lei 10.645/2008, o texto “Altera a Lei No 9.394, de 20 de dezembro 1996, modificada pela Lei No. 10.639, de 9 de janeiro de 2003, que estabelece as diretrizes e bases da educação nacional, para incluir no currículo oficial da Rede de Ensino a obrigatoriedade da temática História e Cultura Afro-Brasileira e indígena". Estes dispositivos garantem oficialmente os desdobramentos dos demais processos de ordenamento institucional para reordenamento situacional.

O olhar para uma educação migratória passa pelas vivências interculturais sobre o foco dos fenômenos das migrações estrangeiras, mas é preciso conhecer as diversidades das africanidades que migraram para Brasil e Mato Grosso, pois mesmo sendo negros, são de diferentes países e diásporas, representando lugares e idiomas diversos.

Em Cuiabá-MT tivemos também a incidência de outros migrantes como os holandeses; alemães; chineses; muitos vieram na década de 1970 com a abertura de Mato Grosso, pós divisão do Estado com o surgimento das cidades ao norte do estado. Já os migrantes haitianos, iniciam suas chegadas em 2005, com poucos registros pela Pastoral do imigrante em Cuiabá, voltando a ter fortes fluxos de chegadas destes, principalmente do Haiti e Moçambique em 2010, com os primeiros anúncios de que o Brasil sediaria a "Copa do Mundo de Futebol em 2014". O Haiti vivia em 2010, um dos piores momentos para além da conjuntura violenta que a população vinha enfrentando. $O$ povo haitiano foi vítima de uma das 
grandes catástrofes climáticas dos últimos anos, um terremoto transformou-se em uma grande tragédia com milhares de mortos, momento que comoveu o mundo. De fato, com o término da Copa de 2014, já tínhamos mais de oito (8) mil migrantes (dados informais dos registros da Pastoral do Imigrante, entidade que recebem a maioria dos migrantes que chegam a Cuiabá).

E por último recebemos os migrantes venezuelanos que vieram como refugiados amparados pela lei publicada no Diário Oficial da União a Lei 13.684/184, que define ações de assistência emergencial para migrantes e imigrantes em situação de vulnerabilidade decorrente de fluxo migratório provocado por crise humanitária" (BRASIL, 2018). Esta lei está referendada na "Medida provisória 820/18, aprovada na Câmara no dia 06 de junho e no senado no dia 12 de junho de 201" (BRASIL, 2018).

Atualmente, depois de três longos anos de luta, nos tornamos o primeiro Estado Brasileiro a normatizar o atendimento aos migrantes estrangeiros, através da Resolução normativa $\mathrm{N}^{\circ}$ 002/2019 publicada no Diário oficial do estado de Mato Grosso N ${ }^{\circ} 27.639$ de 27 de novembro de 2019, resultante da proposta feita pela Comissão de Educação em Direitos Humanos do Conselho Estadual de Educação/MT. Com normas para a oferta da Educação Básica para migrantes estrangeiros, ingressantes no Sistema Estadual de Ensino, significou um grande avanço para a garantia de matrículas para os migrantes estrangeiros.

Nos últimos anos, em virtude desta realidade, muitas reformas educativas são implantadas nos sistemas de ensino e tendem a provocar processos de reelaboração curricular, pois a diversidade passou a influenciar, também, no campo curricular, pelos coletivos diversos (ARROYO, 2008), que por possuírem outros conhecimentos, saberes e culturas, questionam propostas curriculares calcadas em paradigmas de caráter etnocêntricos. Nessa perspectiva Silva (2003) reafirma que:

o currículo é o espaço onde se concentram e se desdobram as lutas em torno dos diferentes significados sobre o social e sobre o político. É por meio do currículo, concebido como elemento discursivo da política educacional, que os distintos grupos sociais, especialmente os dominantes, expressam sua visão de mundo, seu projeto social e suas verdades (p. 10).

Este fato acaba por ocasionar uma série de alterações estruturais e organizacionais sobre o papel da escola e a função docente, consequentemente levando a intervenções no âmbito da formação dos professores (MAUÉS; CAMARGO, 2014).

Assim, frutos deste contexto, os professores acabam por ser alijados da participação nas reformas e na elaboração de políticas de formação que lhe são propostas (quando existentes), em geral pouco comprometidas com o avanço do bem-estar comum, da democracia e da justiça social.

Nessa direção, surge a necessidade de institucionalização de projetos e de reorientações curriculares relacionadas à formação didático-pedagógica dos professores, com vistas a agregar a estes, fundamentação teórica e prática, além de apoio permanente, sobretudo num contexto contraditório de demandas e desafios.

Nessa perspectiva e no sentido de compreender a temática em foco, desenvolvemos uma investigação narrativa sobre as experiências da educação para migrantes estrangeiros, indagando sobre suas experiências e identidades. Ancoramos em Clandinin e Connelly (2011) que ao partirem de Dewey criam um terreno fértil para compreender as experiências, definindo como método a pesquisa narrativa. Quando adotamos a pesquisa narrativa nos posicionamos em uma tridimensionalidade conforme nos apontam os autores citados, cujos olhares se situam numa localidade, numa sociabilidade e numa temporalidade, como caminho para compreender o viver, contar, reviver e recontar das histórias vividas.

\section{CONTEXTUALIZANDO O FENÔMENO DA MIGRAÇÃO}

Ao que parece, as migrações com seus fluxos globais nos levam a ter que repensar nossas políticas

4 -Ver site https://www.camara.leg.br/noticias/541013 
públicas educacionais a partir de que são inevitáveis as transformações causadas nas diversas espacialidades e temporalidades, sob as influências dos fatores geográficos, climáticos e genéticos. Precisamos enfrentar o desafio independente das condições, das vivências interculturais postas nas escolas, nas comunidades e nas sociedades, que tem recebido fortes fluxos migratórios.

O aprendizado a partir do multiculturalismo exige que sejamos capazes de despirmos de nossos etnocentrismos ${ }^{5}$, para apreendermos num ambiente de alteridade e reciprocidade, cujas experiências acontecem em um fluxo de vivenciadas compartilhadas pelo respeito mútuo dos envolvidos. Conforme afirma Canen e Oliveira:

O projeto multicultural, por sua vez, insere-se em uma visão pós-moderna de sociedade, em que a diversidade, a descontinuidade e a diferença são percebidas como categorias centrais. Da mesma forma, contrapondo-se à percepção moderna e iluminista da identidade como uma essência, estável e fixa, o multiculturalismo percebe-a como descentrada, múltipla e em processo permanente de construção e reconstrução (CANEN; OLIVEIRA, 2002, pag.61).

Como podemos verificar o multiculturalismo coloca como necessidade urgente o reconhecimento das multi-relações em constante construção e reconstrução.

O contexto educacional está carregado das narratividades e historicidades contadas e vividas pelos docentes, discentes migrantes que nos levam a uma dimensão educativa própria do sentido migratório, com uma acolhida onde o humano se reconhece humano em sua dimensão de humanicidade. Com a educação escolar para migrantes os profissionais da educação resignificam suas dimensões de acolhida humana nos espaços educacionais. A integração aparece como eixo central e estratégico ao atendimento a migrantes estrangeiros e as escolas necessitam pensar nas possibilidades multilíngues capazes de preparar seus estudantes para o convívio com outros idiomas que não somente o "português" e assim repensar o currículo dotando-o de condições reais para ajudar na apreensão dos códigos básicos de outros idiomas. As matrizes educacionais devem prever nos calendários a inclusão de datas importantes dos migrantes presentes nas escolas, fortalecendo suas raízes e historicidades. Este processo oportuniza trocas constantes de valores e sentidos que passam a se ampliarem reciprocamente, fundindo laços importantes interculturais de solidariedade principalmente nos espaços educacionais.

Desse modo, é importante conhecer os migrantes que chegaram com vistos permanentes, os refugiados e em condições clandestinidade por falta de condições, pois os imigrantes que entram de maneira não regular, muitas vezes necessitam dotar-se de documentações mínimas para que gerem um itinerário formativos de certificação oficialmente pela rede pública, superando irregularidades em suas certificações escolares.

Estes aprendizados estão sendo construídos nas vivências escolares e têm explicitado novos espaços de produção de conhecimentos. Ademais, percebemos que era muito importante conhecermos as histórias de vida dos migrantes haitianos que aqui chegaram trazendo cada qual sua trajetória e significados para que possamos (re)significar os sentidos de suas presenças em nosso território.

Iniciamos o estudo com levantamento dos aspectos necessários para o atendimento das demandas dos Haitianos. Neste sentido as narrativas dos docentes, que atuavam em uma das escolas estaduais foram fundamentais para subsidiar a estruturação do atendimento didático-pedagógico. Assim, constatamos que existia um número considerável de haitianos o que favoreceu o início do atendimento de três (3) turmas de estudantes que passavam por uma classificação e preparação na língua portuguesa

Após início do atendimento junto à escola, num movimento paralelo seguimos reunindo com o sistema estadual de ensino de Mato Grosso, estruturamos uma proposta curricular inicial, que passou a ser utilizada como diretriz para a implantação do atendimento a educação para migrantes estrangeiros. Com base nessa proposta ocorreu a criação junto a SEDUC de dois cargos até então inexistentes nas

\footnotetext{
5 -Etnocentrismo é um conceito da Antropologia definido como a visão demonstrada por alguém que considera o seu grupo étnico ou cultura o centro de tudo, portanto, num plano mais importante que as outras culturas e sociedadeshttps://www.significados.com.br > etnocentrismo
} 
escolas de educação básica, a função do professor intérprete de língua creole e professor integrador. Com base nos dados apontados pelos professores intérpretes e integradores foram instituídas "Regras operacionais pedagógicas-ROP" que visavam a orientação tanto da gestão pedagógica como da gestão administrativa escolar para migrantes estrangeiros. Conforme o que consta nas ROP o estudante migrante que não fala a língua portuguesa estudará a área de linguagem para domínio da língua portuguesa e conforme o seu desempenho neste primeiro momento de sondagem e relatório de desempenho elaborado pelo docente poderá ser promovido à próxima etapa e/ou encaminhado para o exame online ou exame de classificação. Já tanto no $2^{\circ}$ segmento do ensino fundamental quanto para o ensino médio a carga horária de língua portuguesa seria de doze horas (12) semanais.

Atualmente, no Estado de Mato Grosso existem onze escolas estaduais que atendem a estes migrantes e destas, três são escolas situadas em Cuiabá - MT.

\title{
3 EXPERIÊNCIAS NARRADAS NOS CONTEXTOS ESCOLARES: VIVÊNCIAS INTERCULTURAIS
}

Ao pensar na pesquisa narrativa ancorada em Clandinin e Connelly (2011), para construção do processo contínuo de composição de sentidos temos que entender que

\begin{abstract}
É uma forma de compreender a experiência. É um tipo de colaboração entre pesquisador e participantes, ao longo de um tempo, em um lugar ou série de lugares, e em interação com milieus. Um pesquisador entra nessa matriz no durante e progride no mesmo espírito, concluindo a pesquisa ainda no meio do viver e do contar, do reviver e recontar, as histórias de experiências que compuseram as vidas das pessoas, em ambas as perspectivas: individual e social [...] pesquisa narrativa são histórias vividas e contadas (CLANDININ; CONNELLY, 2011, pag.51).
\end{abstract}

No pensar narrativamente as temporalidades contextuais, vão se definindo pelas inter-construções dialógicas do pesquisador com os participantes, nos contextos das experiências envolvidas na dinâmica metodológica do viver, contar, recontar e reviver as histórias, que são imbricadas nas complexidades do singular/universal. Com esse entendimento mergulhamos nos sentidos das experiências vividas pelos migrantes haitianos, para entender a partir deles como valoram suas trajetórias e suas subjetividades, uma vez que a ênfase da pesquisa narrativa está no processo de indagação narrativa.

Dialogando com Castles y Miller pudemos também refletir sobre as singularidades dos migrantes:

(...) la experiencia de la migración y de vivir en otro país, com frecuencia ileva a modificar los planes originales, de modo que las intenciones del migrante en el momento de la partida no son buenas predictoras del comportamiento real. de maneira similar, ningún gobierno se há dado a la tarea de construir una sociedade ...étnicamente diversa através de la inmigración aún. Cuando las políticas recrutamento de mano de obra, com frecuencia conducen a la Formación de minorías étnicas lo que tiene conseqüências a largo plazo para las relaciones sociales, las políticas públicas, la identidad nacional y las relaciones internacionales. Se proporciona un marco teórico para entender las exposiciones más descritivas de la migración, el estabelecimento y la Formación de minorías (CASTLES; MILLER, 2004, p.33)

Ao iniciarmos o estudo narrativo também percebemos a ausência de informações oficiais sobre as políticas públicas em educação para migrantes estrangeiros. Fomos buscar nos espaços das salas de aulas com apoio de algumas indagações iniciais, na tentativa de entender melhor como as dinâmicas didáticopedagógicas vinham sendo implementadas nos contextos das relações étnico-raciais e interculturais nas escolas da rede estadual. Realizamos diálogos nas salas de aulas para migrantes em três (3) escolas estaduais. A princípio pautamos num roteiro de indagações ligadas aos contextos de chegada e permanência na educação. Percebemos que todas as escolas estruturam o atendimento da mesma maneira, ou seja, criavam uma sala somente dos migrantes denominada "sala de classificação", onde os estudantes permanecem até que sejam classificados, tendo como critérios os conhecimentos gerais e a fluência do idioma português. Em seguida, são encaminhados para as salas que lhes é apropriada, conforme sua formação e nível escolar, não sendo ainda instauradas as equivalências de estudos para 
curso técnicos na educação básica.

Em conversas narrativas com os haitianos notava-se a gratidão pela oportunidade de poder estudar numa escola pública, em seus relatos expressavam as dificuldades que encontravam para acessar a educação em seu país de origem onde a educação não é pública. Eles lutam através de muito esforço para poderem elevar os níveis de aprendizagem e cada etapa significa uma grande superação, já que podem chegar a ter que frequentar a escola até por vinte anos se não conseguirem superar os exames de níveis de ensino.

Na escola que é Centro de Jovens e Adultos, participaram de uma conversa coletiva dezesseis (16) estudantes haitianos, que por ali se encontravam. A conversa teve como foco algumas situações motivadoras o caminho percorrido até o Brasil e depois para Mato Grosso. Relatavam que tinham como motivações centrais a busca pelo trabalho, são muitas as manifestações ligadas e este fato, as falas são recorrentes solicitando ajuda para conseguir um emprego e referindo-se à dificuldade de falar o português. Reforçavam a necessidade do trabalho, pois trata-se da manutenção da sobrevivência num país estranho aos seus olhos. Apresentavam uma grande insegurança, mas muitos falavam em terminar os estudos secundários e entrar na universidade ou em uma faculdade particular para conseguir uma vida melhor.

Nos primeiros momentos poucos se expuseram, mas falavam de maneira geral da crise política do Haiti. Foi possível perceber que os migrantes embora sejam haitianos são de regiões diferentes, muitos na zona rural do Haiti, além do fato de virem de situações econômicas diferenciadas alguns entraram através de "coiotes", pelas fronteiras secas, mas chegaram em boas condições emocionais. Expressavam suas necessidades sem o clamor do "sofrimento", mas presenciamos na vivência em sala de aula com os imigrantes o sentido mais profundo do verso "esperançar", reafirmando o que Paulo Freire nos ensina sobre a esperança7. Se revelavam verdadeiros guerreiros e guerreiras, não possuem preconceitos, embora sejam estranhos muitas vezes para nós, mas também se estranham conosco. $O$ "estranhamento" se constitui no espaço entre a construção da reciprocidade, da alteridade e a tomada de consciência de que nossas diferenças não impedem de convivermos e construirmos juntos relações interculturais. Afinal nos contatos com os migrantes e imigrantes somos todos "estranhos" uns aos "outros" e ontologicamente todos nós somos seres em construção, somos humanos inacabados.

Existe nas narrativas da grande maioria dos estudantes uma preocupação com a família sejam os que puderam trazer todo a sua família, sejam os que perderam parte da família no terremoto ou ficaram no país de origem Haiti, sejam aqueles que não têm mais familiares próximos, mas que estão agregados a um grupo que considerava sua família. Há sempre também uma preocupação primeira ligada à busca dos estudos que é o futuro da família como sobreviver, estas preocupações os unem na sobrevivência cotidiana enquanto haitianos.

Apresentaremos alguns fragmentos narrativos desses estudantes para que possamos entender estes clamores, usaremos a denominação "estudante" e um número que diz respeito à ordem dos relatos deles.

Muitas são as narrativas expressando os problemas políticos no país, na realidade eles expressam mais as angústias sobre os problemas políticos e econômicos do país e falam muito pouco do terremoto que sofreram, isto porque mesmo que tenha havido o terremoto, muitos haitianos vieram por outros problemas e estavam em outros países, muito vieram da República Dominicana, outros de Moçambique. Podemos dizer que ao sentirem que havia abertura naquele ano de 2010 para empregos principalmente

\footnotetext{
6-O filósofo Mario Sergio Cortella defende que uma das coisas mais importantes na vida é justamente a esperança, do verbo esperançar, e não do esperar. "Espero que dê certo, espero que resolva. Isso é espera, não esperança. Esperançar, que é de onde vem a palavra esperança, é ir atrás, não desistir". https://www.cvv.org.br/blog/esperanca-do-verbo-esperancar/

7. Segundo Paulo Freire: "É preciso ter esperança, mas ter esperança do verbo esperançar; porque tem gente que tem esperança do verbo esperar”. E esperança do verbo esperar não é esperança, é espera. Esperançar é se levantar, esperançar é ir atrás, esperançar é construir, esperançar é não desistir! https://www.facebook.com > photos > o-que-é-esperançar segundo-paulo-freire ...
} 
na construção civil, muitos vieram com o objetivo de conseguir trabalho. Isto revela que com a crise política muitos haviam migrado a procura de sobrevivência em outros países, e que as informações sobre a oferta de trabalho no setor da construção civil, desencadeou os fluxos migratório rumo ao Brasil.

Desse modo, as diferenças nos contextos educacionais e sociais nos alertaram para algumas contradições e paradoxos que se apresentam como "ambiguidades" nas trajetórias nos colocando numa dimensão de transformação de nossos referenciais, político-pedagógicos, neste campo epistemopolítico, alimentado pela interculturalidade das vivências educacionais.

As primeiras barreiras enfrentadas referem-se aos documentos, como narradas abaixo:

Foi ótimo nossa acolhida, só que quando a gente chegou aqui para arrumar os documentos ficou difícil, por que a gente tem que pagar, mas sem emprego não tem como[...] (estudante-01).

Identificamos que alguns documentos ainda são problemáticos para que os imigrantes possam adquirir maior qualidade de vida, por exemplo, como a situação dos cartórios que cobram dos imigrantes "sem o mínimo de condições econômicas totalmente desprovidos".

Em outras reivindicações os estudantes dizem ter sido bem recebidos e acolhidos, mas solicitam espaço para trabalho, vejam que a situação antes da "Copa do mundo de futebol de 2014" era de disponibilidade de trabalhos, pois a "construção civil" estava em alta, mas a própria característica deste tipo de trabalho era "temporário". Com isso muitos partiram do Brasil e Mato Grosso, mas outros menos qualificados ficaram e buscam emprego, estudo e sobreviverem, como relata o estudante:

Fomos recebidos como se estivéssemos em nosso próprio país. Nem uma pressão, por vezes dificuldades para encontrar trabalho e alguns de nós tem dificuldades em encontrar documentos para viver suas vidas (estudante-02)

Os migrantes busquem as escolas para estudar, sem conseguir resolver os problemas acarretados pela falta de documentações pessoais, pois muitos vieram completamente desprovidos de qualquer documentação, em função de terem vindo com o visto da Embaixada Brasileira no Haiti, portanto não vieram por intermédio dos órgãos oficiais e quando isto não acontece eles ficam sem a carteira de registro migratório-(CRM).

Um problema enfrentado no processo educacional é identificarmos os diferentes níveis de escolaridade já no primeiro acolhimento, ou seja, quando entram no Brasil, independente da forma, no momento que ele tem contato com os órgãos do Estado ou de alguma entidade da sociedade civil. É necessário que seja pensado logo de início em uma triagem para a classificação educacional, isto facilitaria sua inserção na escola pública de educação básica. Os primeiros acolhimentos de migrantes estrangeiros podem ser decisivos para ele, portanto deve ser humanizado e imbuído de compromissos com princípios de garantia dos direitos sociais, econômicos e culturais a todos e todas. Deve ser humanizado enquanto políticas públicas, já que o Estado Brasileiro se compromete pela lei 13.445/2017 garantir o atendimento da saúde, educação entre outros.

Neste sentido, ao falarmos dos migrantes estudantes estes precisam ser reconhecidos como cidadãos e cidadãs em nosso país. A narrativa de um migrante que tem curso superior e está fazendo novamente o estudo do ensino médio por não ter sua documentação, pois esta foi perdida no terremoto, acrescenta:

Do ponto de vista social, eu acho que têm brasileiros agora que estão aprendendo a viver conosco e se acostumando com o jeito e as maneiras da gente. E educacionalmente eu acho um pouco ruim e "estranho" mesmo que uma pessoa imigrante que já tenha acabado seus estudos no Haiti, e que chega aqui tenha que estudar tudo novamente, tive que voltar de novo para traz e completar mais uma vez meus estudos secundários em função do português. Eu acho que o melhor seria que colocar uma estrutura educacional para povos estrangeiros que acabou seus estudos. Para não precisarem voltarem a estudar tudo novamente, as mesmas coisas em função do aprendizado da 
língua portuguesa. E o melhor ainda seria que se a pessoa fala a língua do país atual para fazer exames para ver o nível da pessoa e depois se essa pessoa é bom ou está com um bom nível nos estudos poder ter um jeito para traduzir os papeis escolares, e conseguir entrar para faculdade ou universidade (estudante-03).

Foi possível perceber pelos itinerários dos estudantes dos diferentes países como Haiti e mesmo outros países como República Dominicana, Moçambique, Angola, Cabo verde, Guiné Bissau, Benin, Sudão, países representados aqui em Mato Grosso, que muitos estudantes migrantes vieram com baixíssima escolaridade, outros são mais preparados em termos de escolaridade. Aqueles que chegaram mais preparados fazem a "diferença" nas escolas em relação aos demais e geralmente reclamam o mínimo de tratamento em relação aos direitos a educação. Mesmo atestando que em seus países a educação não seja pública, eles entendem que ao serem aqui atendidos, seria preciso termos programas mais justos para eles em relação ao acesso à educação. Um dos migrantes manifestou profunda insatisfação com a forma de atendimento inicial como estudante, pois já havia concluído o ensino superior em ciências econômicas e estava fazendo novamente o ensino médio.

Estou tentando adaptar é bem difícil para mim, mas eu sempre faço esforço para aprender, eu sou uma pessoa que nunca desistiu de nada, mas está sendo difícil, tem diferença da cultura, nossa maneira de ser, de apreender. No Haiti não precisa de um cartão de identidade para viver isto aqui é estranho. O Brasil é considerado um povo negro com 53\% da população negra, e sempre discriminada, sofre muito preconceitos (verbais, físico e sociais). É sempre mais difícil para uma pessoa negra encontrar um emprego bom, não é o mesmo para uma pessoa branca, em conclusão as pessoas brancas são mais e sempre privilegiadas, e as pessoas negras ao contrário, são discriminadas e colocadas de lado, tenho sentido isto (estudante 04).

Sobre os sentimentos narrados pelo estudante acima, podemos dizer que se trata de como vem se manifestando o racismo institucional, ele apresenta-se como um racismo de "marca" que se manifesta com mais intensidade sobretudo com negros "retintos", que de maneira geral tem fenotípicos negroides, cor da pele, nariz achatado com traços gerais africanoides. O fato de termos passado historicamente por contextos de miscigenações constantes propiciou surgimento de negros de peles mais claras, isto torna as práticas do racismo ainda mais "sutis" para os discriminadores que em funções destas discrepâncias fenotípicas fazem perdurar e fortalecer os discursos da existência de uma "democracia racial" no Brasil.

No entanto, o racismo institucional continua operante nos cotidianos das relações étnico-raciais, quilombolas e interculturais, sem aprofundarmos o fato de que o Estado brasileiro incorporou o discurso "falacioso" da "democracia racial" e estruturalmente invisibilizar as populações negras, sejam por não reconhecer as necessidades especificas em suas ações de políticas públicas, seja por ser inoperante diante dos indicadores sociais dos órgãos oficiais de Estado, que demonstram total descaso ao atendimento destas populações negras. Assim intensificam suas práticas de "racismo institucional" de maneiras cada vez mais sofisticadas.

Atualmente cresce cada vez mais entre os estudiosos e pesquisadores que discutem as relações raciais a posição de que no Brasil se manifesta um racismo de "marca" e não de "origem" esta posição não chega a ser unanimidade mais avança principalmente junto aos movimentos sociais que lutam contra o racismo. Entre os autores que discute esta vertente, temos autores brasileiros que aprofundaram esta tese do racismo de "marca" como o pesquisador Oracy Nogueira (2006), que em seu artigo "Preconceito racial de marca e preconceito racial de origem". Para Nogueira (2006), a educação nas relações étnicoraciais e interculturais, neste momento situa-se em meio aos sentidos dos racismos de "marca e origem" isto posto enquanto elemento de uma conjuntura sócio-política-econômica que terá que coexistir com as diferenças, estranhamentos, multiculturalismo e as afirmações das lutas e resistências culturais e econômicas frente aos pacotes de "austeridades" governamentais que priorizam como foco o desmonte dos direitos sociais básicos, colocando no cenário educacionais brasileiro os maiores desafios na construção de um Projeto Educativo que reconheça as diferenças de gêneros, as raciais, as culturais,

\footnotetext{
${ }^{8}$-de cor carregada, de cor muito escura.
} 
assegurando as riquezas contributivas das dimensões de singularidade posta em cada realidade vivida.

Estas considerações dão um panorama do que significa trabalhar políticas educacionais para migrantes estrangeiros no contexto das relações étnico-raciais e quilombolas, pois entendemos que nossos desafios são ainda maiores, pois somos "referência" na verdade para além do conceito diaspórico afro-brasileiro, somos uma "parte" da África dentro do Brasil.

O autor acima citado nos oferece pistas importantes na busca de garantia de uma educação para os imigrantes estrangeiros, principalmente neste momento de implantação dos direitos obrigatórios postos pelas leis 10.639/2003 e 10.645/2008.

Assim, o desafio da educação para migrantes estrangeiros passa pela formação docente com foco em uma política linguística intercultural mais sobretudo permeada pelo sentido da alteridade enquanto base central de uma pedagogia migratória.

\section{CONSIDERAÇÕES FINAIS}

Considerando o contexto político atual, marcado por desigualdades e negação dos direitos dos coletivos diversos, acreditamos que o recorte deste estudo pode contribuir com estratégias formativas outras aos/as educadores/as engajados/as em propostas curriculares voltadas aos interesses dos coletivos de indivíduos que se encontram em condições de desigualdade e exclusão social.

As reflexões iniciais nos indicou a urgência que temos em conhecer como enfrentar os problemas causados pela globalização e, entre estes, um problema que alcança dimensões mundiais é o que trata da questão das migrações, frente à garantia dos Direitos Humanos para todos. Buscávamos inicialmente, por meio do recorte deste estudo, pensar através das narrativas dos estudantes uma formação para o atendimento aos haitianos aqui em Cuiabá-MT, mas também foi nosso objetivo retratarmos como este fenômeno tem adentrado os muros escolares.

A necessidade de intensificar a luta por justiça social, para a garantia de políticas sociais básicas aos povos migrantes, tem adentrado os muros escolares, uma vez que as marcas trazidas nas mais difíceis trajetórias de suas vidas são legados que, com certeza, nos ensinaram a ser melhores enquanto formadores/docentes e militantes pela garantia de cidadania a todos e todas.

Ressaltamos aqui a importância de se construir referenciais epistemológicos que envolvam os problemas das migrações e entendo que poderíamos continuar a explorar as contribuições dadas pelos estudantes em outro estudo. No entanto, por ora, finalizamos nossas reflexões, sugerindo o desafio de mergulharmos em histórias e narrativas que nos ajudem a interferir de maneira positiva nestes percalços que os povos migrantes vêm enfrentando.

\section{REFERÊNCIAS}

ARROYO, Miguel González. Os coletivos diversos repolitizam a formação. In: DINIZPEREIRA, Júlio Emíllio; LEÃO, Geraldo (Orgs.). Quando a diversidade interroga a formação docente. Belo Horizonte: Autêntica, 2008. p. 11-36.

BRASIL. Constituição da República Federativa do Brasil de 1988. Disponível em: www.planalto.gov.br/ccivil. Acesso em: 19 nov. 2018.

BRASIL. Lei 10.639, de 9 de janeiro de 2003. Altera a Lei no 9.394, de 20 de dezembro de 1996, que estabelece as diretrizes e bases da educação nacional. Brasília: [s.n.], 2003.

BRASIL. Lei 11.645, de 10 de março de 2008. Disponível em: www.planalto.gov.br/ccivil_03/_ato20072010/2008/lei/l11645.htm. Acesso em: 19 nov. 2018.

BRASIL. Diretrizes Curriculares Nacionais Gerais da Educação Básica. Brasília: MEC, SEB, DICEI, 2013. Disponível em: http://portal.mec.gov.br/docman/julho-2013-pdf/13677-diretrizes-educacao-basica2013pdf/file. Acesso em: 14 nov. 2017.

BRASIL. Lei $n^{\circ}$ 12.796, de 04 de abril de 2013. Estabelece as diretrizes e bases da educação nacional, para 
dispor sobre a formação dos profissionais da educação e dar outras providências. Disponível em: http://www.planalto.gov.br/ccivil_03/_Ato2011-2014/2013/Lei/L12796.htm\#art2. Acesso em: 05 abr. 2020.

BRASIL. Base Nacional Comum Curricular. Disponível em: http://basenacionalcomum.mec.gov.br./site/base/. Acesso em: 20 jul. 2018.

BRASIL, Lei n ${ }^{0}$ 13.632, de 06 de março de 2018. Dispõe sobre educação e aprendizagem ao longo da vida. Disponível em: http://www2.camara.leg.br/legin/fed/lei/2018/lei-13632-6-marco-2018786231publicacaooriginal-154957-pl.html. Acesso em: 05 jun. 2019.

CANEN, Ana; OLIVEIRA, Angela Maria. A. Multiculturalismo e currículo em ação: um estudo de caso. Revista Brasileira de Educação, $n^{\circ}$ 21, set-dez. 2002.

CLANDININ, Denise. Jean; CONNELLY, Michael, Pesquisa Narrativa: Experiências e História em pesquisa qualitativa, $2^{\circ}$ Edição revisada, Editora da Universidade Federal de Uberlândia, Uberlândia-MG, 2011.

CASTLES, Stephen; MILLER, Mark J. La era da la migración: Movimientos internacionales de población en el mundo moderno. Traducción: Luís Rodolfo Morán Quiroz. México: Universidad Autónoma de Zacatecas, Instituto Nacional de Migración, Fundación Colosio: Miguel Ángel Porrúa, 2004.

CONSELHO NACIONAL DE EDUCAÇÃO; MINISTÉRIO DA EDUCAÇÃO, SECRETARIA DE EDUCAÇÃO CONTINUADA, ALFABETIZAÇÃO, DIVERSIDADE E INCLUSÃO, Diretrizes Curriculares Nacionais para Educação Básica: Diversidade e Inclusão, Organizado por Cleia Brandão Alvarenga Craveiro e Simone Medeiros, Brasília, Editora Universidade federal de Goiás, 2013.

CONVENÇÃO DE HAIA. Disponível em: https://www.hcch.net/pt/instruments/conventions/specialisedsections/apostille. Acesso em: Acesso em: 20 jul. 2018.

MAUÉS, Olgaíses. Cabral; CAMARGO, Arlete. Maria. Monte de. A expansão do ensino superior, políticas de formação docente e atratividade da carreira. Revista Eletrônica de Educação, v. 8, n. 1, p.77-91, 2014.

NOGUEIRA, Oracy. Preconceito de racial marca e preconceito racial de origem. Tempo Social Revista de Sociologia da USP, São Paulo, Volume 19, Número 1, novembro, 2006.

ORGANIZAÇÃO INTERNACIONAL PARA MIGRAÇÕES. Relatório Migração Global, 2020

SILVA, Tomás Tadeu da. O currículo como fetiche: a poética e a política do texto curricular. Belo Horizonte: autêntica, 2003.

Recebido em: 08/08/2020

Aceito em: $14 / 10 / 2020$

Publicado em: 11/12/2020 